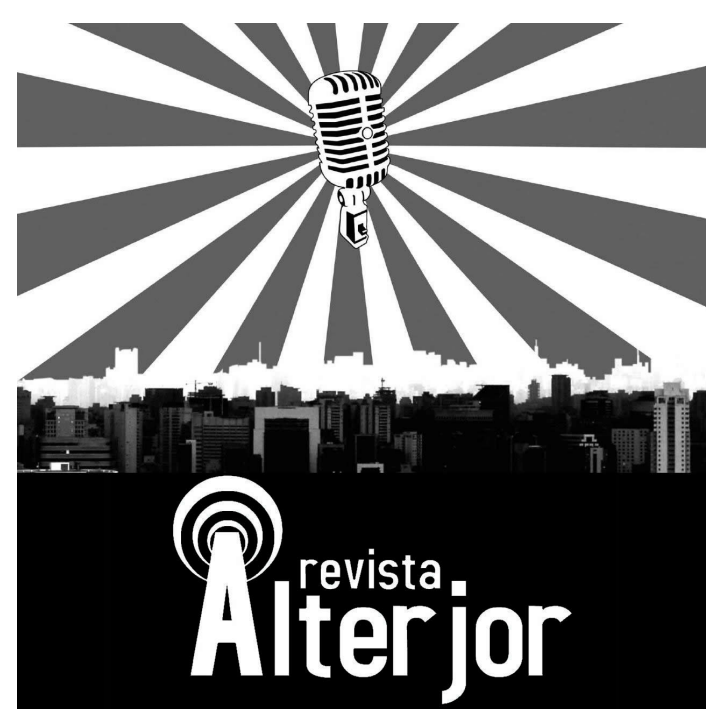

\title{
ESG (ENVIRONMENTAL, SOCIAL AND CORPORATE GOVERNANCE) E A COMUNICAÇÃO: O TRIPÉ DA SUSTENTABILIDADE APLICADO ÀS ORGANIZAÇÕES GLOBALIZADAS
}

\author{
Edwaldo Costa ${ }^{1}$ \\ Nataly Bueno Ferezin ${ }^{2}$
}

RESUMO: Este artigo tem por finalidade discutir o tripé da sustentabilidade ocupando um lugar de destaque nas organizações, ao levar em consideração os três pilares que o sustentam, sendo o ambiental, o social e a governança corporativa. Para isso, o objetivo é apresentar a notória importância da comunicação na gestão da sustentabilidade, dentro das organizações contemporâneas, inseridas na lógica do capital e da sociedade global. Este estudo é um recorte da realidade, e a pesquisa se justifica pelos fatos apresentados e pela importância das informações obtidas por meio de diversos estudos. A metodologia utilizada foi a abordagem bibliográfica qualitativa, e na conclusão da análise verificouse como é promissor trabalhar o ESG alinhado à comunicação organizacional.

PALAVRAS-CHAVE: Organizações. Globalização. Sustentabilidade. Comunicação Organizacional.

\begin{abstract}
This article aims to discuss the tripod of sustainability occupying a prominent place in organizations, considering the three pillars that sustain it, being environmental, social and corporate governance. For this, the objective is to present the notorious importance of communication in sustainability management, within contemporary organizations, inserted in the logic of capital and global society. This study is an example of reality, and the research is justified by the facts presented and by the importance of the information obtained through several studies. The methodology used was the qualitative bibliographic approach, and in the conclusion of analysis it was verified how promising it is to work the ESG aligned with organizational communication..
\end{abstract}

KEYWORDS: Organizations. Globalization. Sustainability. Organizational Communication.

\footnotetext{
${ }^{1}$ Pós-doutor em Comunicação pela Universidade de São Paulo (ECA/USP) e pós-doutorando na Daphne Cockwell School of Nursing, Ryerson University - Canadá. E-mail: edwaldocosta1@gmail.com

Pós-graduada em Gestão Estratégica em Comunicação Organizacional e Relações Públicas pela Universidade de São Paulo (ECA/USP). E-mail: nataly_ferezin@hotmail.com
}

\section{Revista ALTERJOR}

Grupo de Estudos Alterjor: Jornalismo Popular e Alternativo (ECA-USP)

Ano 11 - Volume 02 - Edição 24 - Julho-Dezembro de 2021

Av. Professor Lúcio Martins Rodrigues, 443, Cidade Universitária, São Paulo, CEP: 05508-020 


\section{INTRODUÇÃO}

No mundo globalizado em que a sociedade contemporânea se insere, o desenvolvimento de tecnologias e os meios de comunicação são frequentemente estimulados, levando-os a propagação da informação de maneira instantânea. Essa era do imediatismo que paira no ar e encontra subsídios para sua existência, torna-se cada vez mais líquida, deixando tudo que um dia possa ter sido solidificado com conhecimento ou com o tempo. (BAUMAN, 2007)

Além da liquidez da vida moderna, atualmente a sociedade se depara com uma fragmentação e uma redução de inúmeros conceitos específicos e também do saber e do conhecimento. Esses fatores vão de encontro com o que o pensador Edgar Morin (2000) postula quando fala da complexidade do universo e dos sistemas, e da importância de a totalidade ser agregada aos seus elementos, assim como das partes estarem no todo, pois ambas se correlacionam mutuamente.

Consequentemente, todos esses fatores que afetam o âmbito macro do planeta e do mundo, também comprometem o lado micro, afetando, por exemplo, as organizações e as estratégias de comunicação, constituindo assim uma relação dialética e processual.

As esferas organizacionais e administrativas atuam e são atuadas na/pela globalização inseridas na lógica do capitalismo, onde a criação e a acumulação do capital apresentam-se como o princípio sustentador que condiciona e gera as diretrizes necessárias para a sobrevivência da organização, em um mundo globalizado e voraz por mudanças.

Com essa visão e caminhando neste cenário, todos os tipos de indagações, inquietudes, dúvidas e (in)conclusões se colocaram como cerne do pensamento intelectual para a elaboração do artigo. Em pleno século XXI, não cabe mais a ideia simplista de que somente o capital produzido é que pode sustentar uma organização. Neste momento, a comunicação organizacional encontra seu devido lugar, mostrando aspectos que subsidiam decisões importantes para o crescimento das instituições.

Nas organizações tem se discutido muito amplamente o conceito do tripé da sustentabilidade ou em sua forma original "Triple Bottom Line”, desenvolvido pelo

\section{Revista ALTERJOR}

Grupo de Estudos Alterjor: Jornalismo Popular e Alternativo (ECA-USP)

Ano 11 - Volume 02 - Edição 24 - Julho-Dezembro de 2021 Av. Professor Lúcio Martins Rodrigues, 443, Cidade Universitária, São Paulo, CEP: 05508-020 


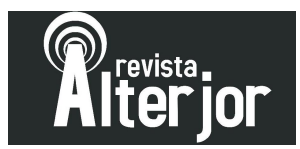

sociólogo inglês John Elkington (2001), no qual são elencados os conceitos de prosperidade econômica, qualidade ambiental e justiça social simultaneamente.

A importância dada a esse exercício de consciência cidadã está sendo atribuída e incorporada por pessoas no mundo inteiro, que acreditam e desejam um futuro melhor. $\mathrm{E}$ as organizações estão seguindo o mesmo raciocínio, debatendo e agregando o novo termo ESG (Environmental, Social and Corporate Governance) ou ASG (Ambiente, Social e Governança Corporativa), como norte para as direções a serem trabalhadas e analisadas, isto é, pensando holisticamente.

O desenvolvimento sustentável não é algo simples de ser aplicado na sociedade atual nem é um estado permanente de harmonia, onde tudo ficará bem e sem problemas, e sim um processo de transformação, que passa por alterações e mudanças constantes, pois envolvem os passos que devem ser seguidos para suprir as necessidades das gerações atuais, de tal maneira que não comprometa os anseios das gerações futuras.

Tendo como base esse cenário desafiador e volátil, este artigo tem como objetivo apresentar a comunicação sendo uma força motriz, cujo direcionamento sobre a sustentabilidade engrandece o êxito das organizações. Além de suscitar discussões, debates, questionamentos, novas ideias, novas propostas, dentro e fora do ambiente da comunicação organizacional, sobre o quão importante é discutir vertentes que afetam a vida humana, direta e indiretamente, partindo de um olhar apurado que contemple as facetas econômica, social e ambiental concomitantemente.

\section{GLOBALIZAÇÃO: a fase contemporânea do capitalismo}

A formação do capitalismo é um processo histórico que surgiu na Idade Moderna ${ }^{3}$ por meio de um modo de produção criado, e seguiu sua história, atingindo seu ápice na Revolução Industrial ${ }^{4}$. A sua existência prega um sistema no qual tudo se torna mercadoria, e pode ser obtida ao se valer de seu valor de troca. A manutenção do capitalismo é mantida pela necessária diferenciação de classes, cujos capitalistas são os

\footnotetext{
${ }^{3}$ Período que compreende do século XV ao século XVIII.

${ }^{4}$ Iniciada na Inglaterra em meados do século XVIII, e devido ao seu acontecimento ocorreu um profundo impacto nos âmbitos econômico e social do processo produtivo posterior à época.
}

\section{Revista ALTERJOR}

Grupo de Estudos Alterjor: Jornalismo Popular e Alternativo (ECA-USP)

Ano 11 - Volume 02 - Edição 24 - Julho-Dezembro de 2021 Av. Professor Lúcio Martins Rodrigues, 443, Cidade Universitária, São Paulo, CEP: 05508-020 


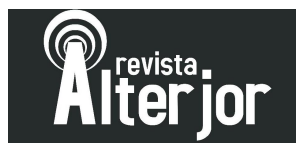

detentores dos meios de produção, e os operários são as pessoas que vendem a força do próprio trabalho como forma de subsistência.

Para que ocorra a evolução do capitalismo, é necessário que se acumule capital para transformá-lo em ações que colaborem com a redução dos custos, elevando a produtividade e aumentando os lucros. Esta é a lógica do capital e das organizações, visar e trabalhar para que se consiga algo, além do retorno investido.

Ocorre que o capitalismo é um processo simultaneamente social, econômico, político e cultural de amplas proporções, complexo e contraditório, mais ou menos inexorável, avassalador. Influencia todas as formas de organização do trabalho e vida social com as quais entra em contato. (IANNI, 2001, p. 172)

Dessa forma, verifica-se de forma processual no capitalismo, que não há separações entre as relações das esferas social, econômica, política e cultural, pois quando se relacionam, todas as imbricações são feitas em todos os âmbitos. Não há a possibilidade de dissociar o pensamento ou fragmentar as vertentes, é necessário entender a complexidade que envolve o atual sistema globalizado e a força com que sofre influência e é influenciado.

Com a evolução da sociedade passando de agrícola para uma era industrial, e logo em seguida pós-industrial, estando hoje em uma era da informação, percebe-se a eficiência e a eficácia com que a comunicação organizacional pode beneficiar a todos dentro do processo social, implicando na cultura de uma sociedade.

Cultura na visão de Geertz (apud MARCHIORI, 2006, p.60) é "Um sistema de concepções expressas herdadas em formas simbólicas por meio das quais o homem comunica, perpetua e desenvolve seu conhecimento sobre atitudes para a vida.", ou seja, para o autor a função da cultura consiste em mostrar ou impor um significado ao mundo para que ocorra o seu entendimento.

Atualmente, o grande desafio colocado para as organizações, encontra-se no fator globalização e seus derivados. Reside e coexiste com este fator, as mudanças impostas de maneira tão brusca e por vezes agressiva, que denotam um mercado dinâmico e extremamente complexo e competitivo.

\section{Revista ALTERJOR}

Grupo de Estudos Alterjor: Jornalismo Popular e Alternativo (ECA-USP)

Ano 11 - Volume 02 - Edição 24 - Julho-Dezembro de 2021 Av. Professor Lúcio Martins Rodrigues, 443, Cidade Universitária, São Paulo, CEP: 05508-020 


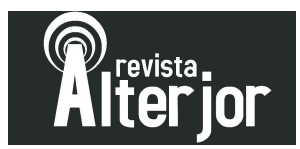

Segundo Santos (2000), no período recente em que o mundo se encontra, algumas bases materiais são importantes para que se pense a respeito da globalização: a convergência do momento, a unicidade técnica e o conhecimento que se tem do planeta.

Nesta forma, a velocidade e a rapidez aplicada às situações vividas relembram o fato de a unicidade do tempo ser essencial para o debate de questões conceituais, pois se o tempo é o mesmo a todo instante e em todos os lugares, ocorre uma convergência dos momentos vividos.

É tudo muito volátil, incerto, complexo e ambíguo nas organizações e acima de tudo, na vida real, pois a obsolescência programada faz agir nos terrenos férteis da vida moderna. Os acontecimentos da vida humana tornaram-se efêmeros e perderam o sentido de valor arraigado a eles, pois o que predomina é o descarte dos objetos, das pessoas e do conhecimento. A vulnerabilidade e suscetibilidade a mudanças são as palavras de ordem. Segundo Bauman (2007, p.8),

A vida líquida é uma sucessão de reinícios, e precisamente por isso é que os finais rápidos e indolores, sem os quais reiniciar seria inimaginável, tendem a ser os momentos mais desafiadores e as dores de cabeça mais inquietantes. Entre as artes da vida líquido-moderna e as habilidades necessárias para praticá-las, livrar-se das coisas tem prioridade sobre adquiri-las.

Entender essa relação e aprofundar em sua análise é essencial para a compreensão acerca das organizações contemporâneas, as quais necessitam ter em seu quadro de colaboradores, profissionais de diversas áreas que possam se entrelaçar e juntos fazer a diferença. Mostrando dessa forma, a importância dos mais variados conhecimentos e saberes ao se interligarem, e da comunicação feita entre eles, de maneira endógena na organização, assim como a relação exógena que deve ser mantida fora dos limiares físicos desse aparato.

Em outras palavras, quando a globalização se traduz no processo de horizontalização de valores, perspectivas, ética, ela se mostra altamente positiva. Quando vertical, ao contrário, ela é negativa e reveladora de uma nova forma de hierarquização de cidadãos e dominação da elite. Neste caso, ela difunde a lógica da apartação social, em contraponto à lógica da cidadania, na construção de padrões de civilidade. (SPOSATI apud DOWBOR, 1997, p. 44)

\section{Revista ALTERJOR}

Grupo de Estudos Alterjor: Jornalismo Popular e Alternativo (ECA-USP)

Ano 11 - Volume 02 - Edição 24 - Julho-Dezembro de 2021 Av. Professor Lúcio Martins Rodrigues, 443, Cidade Universitária, São Paulo, CEP: 05508-020 


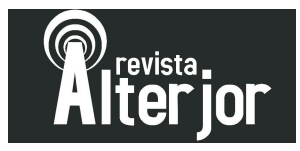

Neste sentido, a globalização deve lidar concomitantemente com o exercício de cidadania e civilidade dos indivíduos, aliando ao capital as inovações da contemporaneidade. No momento em que as organizações horizontalizam as relações humanas nela imbricadas, há uma postura diferente por parte de todos, principalmente dos colaboradores, fazendo com que isso reflita de maneira benéfica nos valores e na ética de cada um, e da organização como um todo.

\section{ESG (ENVIRONMENTAL, SOCIAL AND CORPORATE GOVERNANCE): o tripé}

Segundo Milton Santos (2000, p.25), "Na história da humanidade é a primeira vez que tal conjunto de técnicas envolve o planeta como um todo e faz sentir, instantaneamente, sua presença.", isto é, o ser e o entender do porquê da existência humana na Terra tornou-se um diferencial, um algo a mais nas pessoas, tanto como ser humano, quanto como profissional, dentro das organizações onde se trabalha.

A sustentabilidade é vista na atualidade, como um fator primordial nas decisões dentro das organizações globalizadas. Os índices que mostram a verdadeira sustentabilidade, e não o efeito greenwashing ${ }^{5}$, dentro das organizações são cada vez mais valorizados e discutidos no ambiente corporativo, chegando até obter importância nas Bolsas de Valores mundiais, fazendo as ações de organizações sustentáveis serem mais rentáveis que de organizações não tão preocupadas com esta questão, que já passou do nível de relevante para essencial.

A cognoscibilidade do planeta mostra fontes essenciais para as organizações contemporâneas, afinal todo o conhecimento está interligado e conhecendo-o, existe a possibilidade de saber como lidar previamente ou gerenciar determinadas situações de risco ou de crise. Agregando estas informações ao trabalho desenvolvido pela comunicação, os resultados serão extremamente benéficos para todos.

As noções de ecossistema sempre serão pautadas pelas questões que se referem à integração dos seres, a complexidade presente em cada um e o caráter funcional e sistêmico que envolve todos os fatores que fazem parte do todo. Em conjunto com a ideia

\footnotetext{
${ }^{5}$ Consiste na falsa aparência de sustentabilidade, ao promoverem técnicas para serem vistas no mercado, as quais não são a real intenção da empresa.
}

\section{Revista ALTERJOR}

Grupo de Estudos Alterjor: Jornalismo Popular e Alternativo (ECA-USP)

Ano 11 - Volume 02 - Edição 24 - Julho-Dezembro de 2021 


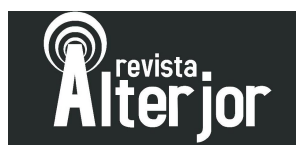

de ecossistema, deve ser analisada a noção e percepção de cultura também, pois existem muitas relações entre ambas que se convergem, devido ao fato de a cultura também lidar com relações sociais e a complexidade de determinadas ações dentro destas. Segundo Altvalter afirma,

\begin{abstract}
Aliás, a destruição de muitas culturas nativas ocorre paralelamente à destruição de ecossistemas, dos quais, de certa forma, os povos portadores dessa cultura eram guardiões. A diversidade cultural, muitas vezes, corresponde à biodiversidade, ambas em processo histórico de destruição a partir do avanço do industrialismo e do consumismo desenfreado que caracterizam o homem contemporâneo, embriagado pelo desenvolvimento tecnológico que destrói a natureza e que promoverá a destruição de recursos não-renováveis, como os combustíveis fósseis, os quais o Sol levou bilhões de anos para criar, em nosso planeta, e consumimos em segundos, graças ao modelo de gasto energético distorcido praticado pelo nosso tipo de civilização. (apud WHITAKER; BEZZON, 2006, p.67)
\end{abstract}

Em culturas semelhantes às descritas, a destruição do seu entorno sociocultural e de seu ecossistema, além de seus valores internalizados, é perpassada exclusivamente pela vontade destemida do homem de ter a dominação em suas mãos, não se importando com as consequências de suas ações, muito menos com as futuras gerações. Essa ânsia pelo poder vem destruindo recursos de forma mais enfática, desde a Revolução Industrial, devido à necessidade inconsciente de produzir riquezas destruindo a natureza.

A sociedade do consumo vivenciada nessa era pós-moderna traz à tona a efemeridade de tudo e de todos, desde produtos até as relações humanas, o que causa o descarte inconsciente daquilo que não satisfaz mais, e gera lixo em todos os aspectos, tecnológico, ambiental, informacional e também humano.

Um dilema latente nos dias de hoje baseia-se no questionamento do que é necessário para cada pessoa, consumir para viver ou viver para consumir? Existem inúmeras possibilidades que são mostradas para os consumidores, opções diferentes de modelos, cores, cheiros, texturas, sabores, tecnologia, enfim são construídas alternativas para incitar as pessoas a comprarem e consumirem de maneira frenética. O desejo por ter ou possuir algo se torna instantâneo, da mesma forma que acaba quando é realizado, a

\title{
Revista ALTERJOR
}

Grupo de Estudos Alterjor: Jornalismo Popular e Alternativo (ECA-USP)

Ano 11 - Volume 02 - Edição 24 - Julho-Dezembro de 2021 Av. Professor Lúcio Martins Rodrigues, 443, Cidade Universitária, São Paulo, CEP: 05508-020 


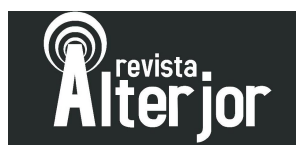

vontade vem e vai, tomando um contorno e um comando abrupto das situações, de maneira efêmera como diz Bauman (1999, p. 91),

Não tanto a avidez de adquirir, de possuir, não o acúmulo de riqueza no seu sentido material, palpável, mas a excitação de uma sensação nova, ainda não experimentada - este é o jogo do consumidor. Os consumidores são primeiro e acima de tudo acumuladores de sensações; são colecionadores de coisas apenas num sentido secundário e derivativo.

A obsolescência programada apresenta-se como um dos grandes males da humanidade, além de ser um desafio, pois nada parece ser mais sólido, durável e completo, tudo é mostrado de forma líquida, uma vida líquida, relações líquido-modernas, amores líquidos, tempo líquido, medo líquido, vive-se uma modernidade líquida e fluida como afirma Bauman (1999). O consumo exacerbado causa uma produção numerosa de lixo e de descarte, fator inadmissível para vias sustentáveis. Capra (2005, p.167) afirma,

O ressentimento contra a globalização econômica está crescendo rapidamente em todas as partes do mundo. Pode ser que o destino último do capitalismo global seja, nas palavras de Manuel Castells, 'a rejeição social, cultural e política, por parte de um grande número de pessoas no mundo inteiro, de um autômato cuja lógica ignora ou desvaloriza a humanidade dessas pessoas'.

A cultura da sociedade de consumo cresce cada vez mais, em proporções exponenciais, seguidas de consequências maléficas a população, tão grandiosas quanto às próprias ações. Neste contexto, o consumo consciente é que encontra nas brechas do capitalismo um lugar para atuar e autuar todos os cidadãos, como mostra

Vivemos na hipermodernidade, definida pelo filósofo francês Gilles Lipovetsky e caracterizada pela cultura do excesso, do sempre mais, da exacerbação do consumo, do individualismo e do modo de vida em que todas as coisas são intensas e urgentes. [...] Hoje, nosso entorno é complexo, e estamos prestes a nos inviabilizar como espécie. A possibilidade é concreta. E alarmante. Aos poucos, ao longo dos últimos anos, vê-se crescer a quantidade e a profundidade de consciências. Pessoas passaram a adotar hábitos menos agressivos, empresas adotaram - boa parte ainda como retórica, puro discurso - o conceito de sustentabilidade, palavra que anda de boca em boca mundo afora. Outras assumiram de fato um compromisso com o mundo e não só

\section{Revista ALTERJOR}

Grupo de Estudos Alterjor: Jornalismo Popular e Alternativo (ECA-USP)

Ano 11 - Volume 02 - Edição 24 - Julho-Dezembro de 2021 Av. Professor Lúcio Martins Rodrigues, 443, Cidade Universitária, São Paulo, CEP: 05508-020 


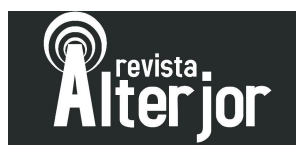

repensam seus processos para torná-los amigáveis ao futuro, como disseminam a ideia. (NASSAR apud CEBDS ${ }^{6}, 2010$, p.4)

Dentro dessa lógica e partindo da premissa de que os tempos mudam, e as pessoas também mudam, enfim, tudo se altera de maneira dialética, em constantes movimentos processuais, verifica-se a importância que a comunicação organizacional ocupa levando à propagação de ideias motivadoras para um mundo melhor. Ao propor no interior de organizações globalizadas, que sejam trabalhados tais conceitos e denominações que levem em conta as inovações e descobertas surgidas ultimamente, muitas reações irão surgir, tanto positivas quanto negativas.

A resistência irá aparecer, pois esses pensamentos podem parecer para algumas pessoas ou grupos, muito radicais ou contraditórios, e até mesmo retrógrados. E é nesse lugar-comum que muitos pensam e agem, onde a comunicação organizacional encontra um terreno fértil para atuar e levantar discussões, exercendo o seu papel com total eficiência e eficácia no processo.

Partindo destas análises da sociedade de consumo, e o gasto que isso resulta para a humanidade, torna-se importante entender de maneira estruturada a visão de Elkington (2001) sobre o tripé da sustentabilidade.

O primeiro pilar seria o econômico que já parte do princípio básico dentro da maioria das organizações, pois visa o capital e o lucro. Embutido na palavra capital, algumas denominações específicas aparecem como, por exemplo, capital físico representando a parte estrutural da organização, capital financeiro que denota a parte monetária, capital humano o qual é constituído pelas experiências e conhecimentos dos indivíduos que compõem a organização e capital intelectual que representa os fatores abstratos imbricados no intelecto, e um dos mais valiosos na atualidade para as organizações contemporâneas.

Logo depois, vem o pilar ambiental, talvez o mais importante nessa tríade, pois direciona a maioria das outras ações, tanto econômicas, quanto sociais. Os fatores relacionados ao meio ambiente estão se colocando a frente de muitos outros, pois sua

\footnotetext{
${ }^{6}$ CEBDS - Conselho Empresarial Brasileiro para o Desenvolvimento Sustentável.

\section{Revista ALTERJOR}

Grupo de Estudos Alterjor: Jornalismo Popular e Alternativo (ECA-USP)

Ano 11 - Volume 02 - Edição 24 - Julho-Dezembro de 2021 Av. Professor Lúcio Martins Rodrigues, 443, Cidade Universitária, São Paulo, CEP: 05508-020
} 


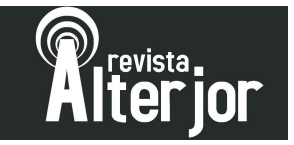

urgência já atinge o planeta e seus habitantes, nas suas mais variadas formas, como sua fauna e flora e principalmente, seres humanos.

Segundo John Elkington (2001, p.83) "O interesse sobre o pilar ecológico das empresas é como a capacidade de suporte da maioria dos ecossistemas varia em relação ao número - e comportamento - dos atores econômicos que operam neles." Ainda nesse campo, as pesquisas acerca da contabilidade ambiental ou os indicadores, responsabilidades e tendências são relativamente muito recentes no âmbito da história. Contudo, o pouco que existia está gerando o muito que está por vir, afinal ocorre uma crescente demanda por essa área, visto que seu crescimento atinge níveis espetaculares dentro de certas organizações.

E o terceiro pilar é o social que compõe e é uma parte fundamental desse tripé, diferente do que muitos envolvidos nessa questão pregam dizendo que assuntos e demandas culturais e sociais não possuem nenhuma forma de relação com 0 desenvolvimento sustentável. Inserido nesse pilar encontra-se o conceito de capital social denominado pelo autor como,

Uma medida da 'capacidade de as pessoas trabalharem juntas, em grupos ou organizações, para um objetivo comum'. Essa capacidade é crítica para a transição da sustentabilidade. Ela pode ser desenvolvida (ou destruída) em todos os níveis de uma sociedade, de unidade básica familiar até as principais instituições de governo internacional. Isso depende da aquisição e da manutenção de virtudes como fidelidade, honestidade e dependência. (ELKINGTON, 2001, p.89)

Com a crescente diversidade e conhecimento da capacidade organizacional surgem novas variações conceituais, como capital natural que se torna bem complexo de explicar, pois as riquezas naturais não se resumem a dados pontuais e simples contagens numéricas, mas sim ao valor agregado que isso gera para todo o ecossistema, e por consequência, para as organizações.

O tripé encontrado nas organizações globalizadas, recentemente chamado pela abreviação de ESG para resumir as práticas adotadas, substituiu o fator econômico para o termo governança corporativa, pois amplia a visão e não somente engloba o resultado comercial, mas também a transparência nesta divulgação, os comitês de auditoria, a conduta corporativa e o combate à corrupção

\section{Revista ALTERJOR}

Grupo de Estudos Alterjor: Jornalismo Popular e Alternativo (ECA-USP)

Ano 11 - Volume 02 - Edição 24 - Julho-Dezembro de 2021 Av. Professor Lúcio Martins Rodrigues, 443, Cidade Universitária, São Paulo, CEP: 05508-020 


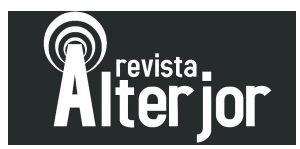

Esse campo do ESG tende a cada vez mais demarcar seu lugar, encontrar seu caminho, fazer sua história neste mundo, pois não se trata mais de desdenhar ao dizer que são meras questões de políticas ambientais de determinado governo. Os pontos a serem desencadeados por pessoas influentes nesse tipo de cenário já foram levantados, como forma de um primeiro passo nessa longa caminhada que a humanidade está por fazer. Esse reconhecimento dos problemas instaurados já resultou na disseminação desse pensamento sustentável, o que pode ser visto como um segundo passo, pois a conscientização de algumas pessoas e suas próprias decisões de mudanças de hábitos e atitudes podem aguçar as dúvidas de outros, e assim a transformação engatinha para uma direção sustentável.

\section{COMUNICAÇÃO}

Entender e compreender o mundo globalizado é um pressuposto básico para que possa ser entendido o processo de comunicação, seu papel na atualidade, os desafios a que é submetida e os debates e discussões que surgem, pois a importância da comunicação e da informação são como meios para a expansão do conhecimento.

A comunicação humana pressupõe que exista um processo, no qual ocorra a troca de mensagens entre os interlocutores. A palavra comunicação vem do latim comunicare que pode atribuir dois sentidos distintos, sendo o primeiro com o intuito de partilhar algo, tornar comum, exercer a comunhão entre algo. O segundo propõe ceder à informação, conceber o ato de informar dando conhecimento a alguém.

Os significados do ato de comunicar, não necessariamente se divergem entre si devido a serem derivados da mesma etimologia da palavra, porém talvez na prática sejam utilizados ou agregados de maneiras diferentes, levando a um pensamento que questione seus modelos ou práticas.

Na primeira visão quando ocorre a partilha de algo ou há a comunhão, nota-se uma relação de horizontalidade, na qual as pessoas estão nos mesmos patamares sociais, o olhar perante o outro é lançado de forma a verificar uma ligação entre eles, ou semelhanças que o levaram a partilharem algo em comum para ambos.

\section{Revista ALTERJOR}

Grupo de Estudos Alterjor: Jornalismo Popular e Alternativo (ECA-USP)

Ano 11 - Volume 02 - Edição 24 - Julho-Dezembro de 2021 Av. Professor Lúcio Martins Rodrigues, 443, Cidade Universitária, São Paulo, CEP: 05508-020 


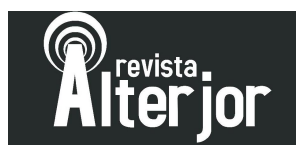

Entretanto, no segundo ponto de vista partindo do momento em que é cedida a informação a alguém, verifica-se uma hierarquização no processo comunicacional, no qual relações de verticalidade podem ser forçadas a atuar, determinando assim diferenças entre os interlocutores.

$\mathrm{O}$ ato de informar e a noção de dar a informação mostra o emissor como sendo um agente ativo que detém isto, e o receptor com um papel de passividade, que receberá e interpretará a informação, ajustando-a a sua realidade.

\begin{abstract}
A sociedade necessita imprescindivelmente da comunicação, tanto nos meios quanto de toda a convergência midiática. Somente com a comunicação será possível conscientizar a população em geral, os governos, a iniciativa privada e os segmentos representativos da sociedade civil de que o atendimento às necessidades e aspirações do presente sem comprometer a possibilidade de atendê-las no futuro é uma tarefa de toda a sociedade mundial e não só de uma pessoa, de uma só organização e de um só país. (KUNSCH, 2009. p. 70)
\end{abstract}

Dessa forma, a comunicação é algo essencial para a existência humana para converter os meios aos quais as mensagens são transportadas. Elaborar meios que sensibilizem e conscientizem as pessoas sobre quão fundamental são as medidas sustentáveis no cotidiano é um método que faz parte das ações de comunicação.

Nesse sentido, as organizações contemporâneas também devem assumir seus papéis de destaque perante a sociedade civil. Por isso, é significante frisar a importância que as organizações possuem no contexto da sociedade capitalista global, tendo responsabilidades e atitudes que são repassadas para o mundo, podendo ser utilizadas de maneira errônea, se não forem bem empregadas.
As organizações devem preocupar-se cada vez mais com o monitoramento das informações e a abertura do diálogo com seus diferentes públicos de interesse, entendendo que seu comportamento deve ir além do repasse de informações. Na realidade, é preciso atuar no sentido de selecionar informações que façam parte do contexto vivenciado pela empresa e que tenham sentido para os públicos, produzindo assim uma comunicação que gere atitude. (MARCHIORI, 2006, p.24)

Assim, notam-se as possibilidades que podem se abrir, quando o diálogo é estabelecido entre as partes envolvidas no processo. É fundamental o debate de ideias e argumentos demonstrando os diversos pontos de vista. Esta abertura em optar pelas falas

\title{
Revista ALTERJOR
}

Grupo de Estudos Alterjor: Jornalismo Popular e Alternativo (ECA-USP)

Ano 11 - Volume 02 - Edição 24 - Julho-Dezembro de 2021 Av. Professor Lúcio Martins Rodrigues, 443, Cidade Universitária, São Paulo, CEP: 05508-020 


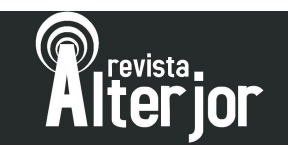

que muitas organizações adotaram, traz muitos benefícios para ambos, tanto para si próprios, quanto para todos os stakeholders ${ }^{7}$, pois o todo deve ser constituído por partes que se engajem no processo, levando suas opiniões, levantando questões e apontando acertos e falhas que os afetam.

Nesse ambiente, a comunicação aparece como uma mola propulsora para gerenciar as relações em questão, viabilizando todos os processos de mudanças envolvidos, fazendo com que ocupe um papel fundamental dentro do cenário global.

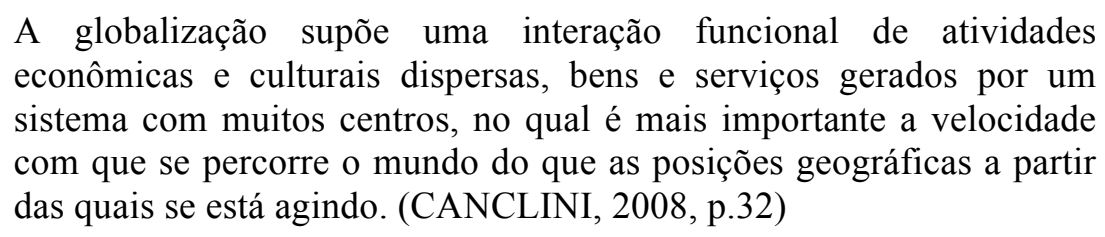

Em um ambiente globalizado, onde a comunicação se tornou algo instantâneo, com uma velocidade que desafia os limites de tempo e espaço, as atividades por ela a serem desenvolvidas, possuem uma capacidade surpreendente de absorver novas informações a todo momento, gerando outras, e levando tudo de forma simultânea ao redor do planeta. Waldir Gutierrez Fortes afirma que "As pessoas estão transferindo o foco de suas idiossincrasias que, nos anos 60 e 70, se concentravam na autogratificação e na autorrealização. Agora surge uma 'sociedade-do-nós', mais coletiva.” (FORTES, 2003, p.91).

A dialética e a dinâmica de fatores sociais e econômicos ocorridos ao longo da história mostraram para as organizações e os indivíduos, a importância da comunicação organizacional ser bem trabalhada fazendo as interrelações necessárias com outros setores, para atingir os objetivos das ações comunicacionais.

Dentro da sociedade global, Kunsch (2003) analisa o processo do fenômeno comunicacional, como funciona o sistema e o funcionamento entre os stakeholders e a organização, pontuando a comunicação organizacional, além de formar o composto denominado comunicação integrada, que abarca quatro tipos diferentes de comunicação, a institucional, a mercadológica, a administrativa e a interna.

\footnotetext{
${ }^{7}$ Stakeholders são os públicos de interesse.
}

\section{Revista ALTERJOR}

Grupo de Estudos Alterjor: Jornalismo Popular e Alternativo (ECA-USP)

Ano 11 - Volume 02 - Edição 24 - Julho-Dezembro de 2021 


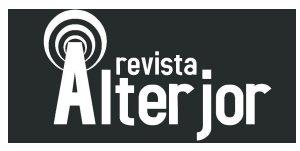

A comunicação institucional objetiva construir e estabelecer uma identidade organizacional e a boa imagem da empresa perante seus públicos de interesse, utilizandose de estratégias de relações públicas. Já a comunicação mercadológica visa melhorar, com divulgação publicitária, a imagem dos produtos ou serviços oferecidos perante o mercado, trabalhando bastante com o marketing. (KUNSCH, 2003)

A comunicação administrativa tem por finalidade repassar as informações e os conteúdos processados dentro da organização, estabelecendo fluxos e redes no âmbito das funções administrativas, para que todos os setores possam analisar o processo. E a comunicação interna vislumbra a construção do diálogo entre a organização e seus colaboradores, os quais são indivíduos que podem estruturar participações e um canal de troca de informações, tornando-se multiplicadores institucionais.

Os caminhos que a comunicação encontra para atuar nesse ramo da sustentabilidade são desafiadores, pois são novidades que devem ser testadas, usadas e acertadas ao mesmo tempo. A divulgação da comunicação do que está sendo feito e do que será feito dentro de cada organização é elencada como uma das principais atividades que deve ser desenvolvida pelo setor de comunicação. Muitos relatórios e guias estão sendo apresentados à sociedade e a setores envolvidos, onde se demonstram índices, pautas, metas e objetivos sustentáveis elaborados e desenvolvidos naquela organização. E onde observa-se até que ponto é realizada uma comunicação na gestão da sustentabilidade realmente.

Dessa forma, a complexidade da sustentabilidade que está presente dentro e fora das organizações globalizadas contempla uma nova maneira de ver o mundo, e realizar ações para melhorias.

Nesse sentido, a sustentabilidade pressupõe a percepção da complexidade. Ela só concretiza na medida em que se alastra por todas as cadeias econômico-produtivas no mundo, bem como pelas práticas humanas mais triviais, como a da classificação do que é lixo e do descarte do lixo. Essa disseminação de novos padrões de hábitos, comportamentos e decisões, dos níveis microssociais aos níveis macrossociais, depende, necessariamente, da comunicação de novos valores. No entanto, não se chegou ainda a um patamar em que se produzam comunicações uníssonas em torno da mudança global de padrões e comportamentos sustentáveis. (SOARES apud KUNSCH, 2009, p.29)

Revista ALTERJOR

Grupo de Estudos Alterjor: Jornalismo Popular e Alternativo (ECA-USP)

Ano 11 - Volume 02 - Edição 24 - Julho-Dezembro de 2021 Av. Professor Lúcio Martins Rodrigues, 443, Cidade Universitária, São Paulo, CEP: 05508-020 


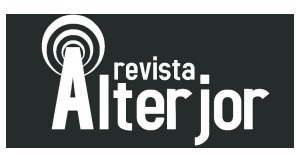

O comportamento das pessoas que se envolvem e participam de atividades com o tema sustentável, em certa medida, é incorporado pelos novos valores que foram construídos e edificados por uma consciência coletiva que vem perpassando pelas pessoas, na época atual.

Portanto, considera-se que na medida com que as práticas ambientais, sociais e de governança corporativa se alastram pelo planeta disseminando suas ideias e seus ideais, novos hábitos e novas condutas começam a ser introduzidos, atingindo todos os níveis. As organizações que adotarem nas suas estratégias de comunicação, ESG como norte para seu trabalho, consequentemente estarão em um outro patamar de visibilidade.

\section{CONSIDERAÇÕES FINAIS}

No passado, o capitalismo buscava encontrar recursos que gerassem lucros e mão de obra barata, pois era a demanda da época e a visão organizacional do sistema. Agora na sociedade contemporânea globalizada, as mudanças ocorrem constantemente e afetam ambientes macros e micros de forma dialética. O principal diferencial que deve ser apresentado nesse mundo da globalização encontra-se no conhecimento e na informação, na geração inovadora que a constitui.

Após o debate sobre o ESG que engloba as esferas ambiental, social e governança corporativa, trabalhadas nas organizações globalizadas de forma conjunta, concluiu-se que o processo de composição desta tríade não leva a fragmentação das partes, mas sim a percepção da complexidade que a envolve e as interrelações que compõe ao aplicá-la às organizações contemporâneas.

Ao verificar esse pensamento complexo que busca juntar o dissociado e restaurar o fragmentado, os reducionismos e a linearidade presente no método cartesiano e mecanicista encontram-se de subsídio para o surgimento das inquietudes, indagações e questionamentos presentes. A tentativa de compreensão e explicação das incertezas remete ao indivíduo pensar em uma reforma, junto a uma reforma do próprio pensamento.

Nesta conjuntura, a comunicação organizacional deve trabalhar com ESG de maneira sincronizada, elaborando estratégias com os seus públicos de interesse, de tal forma que sempre analise o sujeito ocupando diversos papéis, os quais não se separam, e

\section{Revista ALTERJOR}

Grupo de Estudos Alterjor: Jornalismo Popular e Alternativo (ECA-USP)

Ano 11 - Volume 02 - Edição 24 - Julho-Dezembro de 2021 Av. Professor Lúcio Martins Rodrigues, 443, Cidade Universitária, São Paulo, CEP: 05508-020 


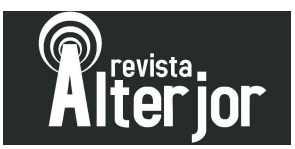

o colocando diante de um sistema organizacional que precisa manter uma visão de totalidade.

Conclui-se que é fundamental os profissionais da área de comunicação mostrarem os aspectos do ESG de forma global para a organização, contextualizando o saber e o conhecimento, para fazer inserções nas culturas locais e aplicá-las da melhor forma possível, visando algo processual que demanda a troca de saberes e gere resultados positivos para todos. Desse modo, aumentam as esperanças na crença de que em breve possa surgir um capitalismo sustentável, que pregue mudanças e atitudes coerentes com a realidade atual do planeta, levando em conta a demanda necessária para a sobrevivência humana na Terra,

Ao fechar uma questão, a ordem ressurge e se estabelece como o que seria uma forma do correto, contudo, a desordem é necessária para que o sistema não cristalize e o pensamento não cesse, fazendo com que as inquietudes continuem latentes nos indivíduos e as indagações os incomodem, incitando-os a questionar o porquê das coisas.

Por fim, este trabalho não é uma obra que esgota e encerra este assunto, nem se propõe a isso, ao contrário, terá atingido seus objetivos se conseguir despertar em cada leitor as reflexões contidas no artigo sobre a comunicação e ESG, agregando conhecimento ao repertório e a acuidade intelectual.

\section{REFERÊNCIAS}

BAUMAN, Z. Globalização: as consequências humanas. Rio de Janeiro: Jorge Zahar Editora, 1999.

BAUMAN, Z. Vida líquida. Rio de Janeiro: Jorge Zahar Editora, 2007.

CANCLINI, N. G.. Consumidores e cidadãos: conflitos multiculturais da globalização - $7^{\mathrm{a}}$ edição - Rio de Janeiro: Editora UFRJ, 2008.

CAPRA, F. As conexões ocultas: ciência para uma vida sustentável. São Paulo: Cultrix, 2005.

CEBDS - Conselho Empresarial Brasileiro para o Desenvolvimento Sustentável. Guia da Comunicação e da Sustentabilidade. 2010. Disponível em http://www.communita.com.br/assets/23_guia-de-comunicacao-esustentabilidade_cebds.pdf Acessado em 10 junho 2021.

\section{Revista ALTERJOR}

Grupo de Estudos Alterjor: Jornalismo Popular e Alternativo (ECA-USP)

Ano 11 - Volume 02 - Edição 24 - Julho-Dezembro de 2021 Av. Professor Lúcio Martins Rodrigues, 443, Cidade Universitária, São Paulo, CEP: 05508-020 


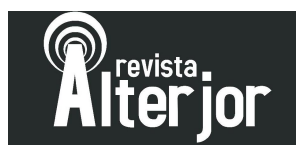

DOWBOR, L.; IANNI, O. RESENDE, P. E. A. (Org.) Desafios da globalização. - $4^{\mathrm{a}}$ edição - Rio de Janeiro: Vozes, 1997.

ELKINGTON, J. Canibais com garfo e faca. São Paulo: MAKRON Books Ltda, 2001.

FORTES, W. G. Relações públicas: processo, funções, tecnologia e estratégias - $2^{\mathrm{a}}$ edição revisada e ampliada - São Paulo: Summus, 2003.

IANNI, Octávio. Teorias da globalização. - $9^{a}$ edição - Rio de Janeiro: Civilização Brasileira, 2001.

KUNSCH, M. M. K. Planejamento de relações públicas na comunicação integrada. - $4^{\text {a }}$ edição - São Paulo: Summus, 2003

KUNSCH, M. M. K; OLIVEIRA, I. L. (Org.) A comunicação na gestão da sustentabilidade das organizações. São Caetano do Sul, SP: Difusão Editora, 2009.

MARCHIORI, M. Cultura e comunicação organizacional. São Caetano do Sul, SP: Difusão Editora, 2006.

MORIN, E. Saberes globais e saberes locais: o olhar transdisciplinar. Rio de janeiro: Garamond, 2000.

MORIN, E. A terra como pátria. In: MANCINI, R. et al. (Org.) Éticas da mundialidade: o nascimento de uma consciência planetária. São Paulo: Paulinas, 2000.

SANTOS, M. Por uma outra globalização: do pensamento único à consciência universal. - $4^{\mathrm{a}}$ edição - Rio de Janeiro: Record, 2000.

WHITAKER, D. C. A.; BEZZON, L. A. C. A cultura e o ecossistema: reflexões a partir de um diálogo. Campinas, SP: Editora Alínea, 2006. 